\title{
A TEMÁTICA DAS UNIÕES HOMOAFETIVAS NO SUPREMO TRIBUNAL FEDERAL À LUZ DO DEBATE HONNETH-FRASER
}

\author{
Maria Eugenia Bunchaft
}

THE ISSUE OF HOMOSEXUAL UNIONS IN THE FEDERAL SUPREME COURT IN LIGHT OF THE DEBATE HONNETH-FRASER

\section{RESUMO}

O DEBATE SOBRE OS DIREITOS DAS UNIŌES HOMOAFETIVAS CONSTITUI UM DOS TÓPICOS MAIS CONTROVERSOS DO DIREITO CONSTITUCIONAL. COMO SE SABE, A UNIÃO HOMOAFETIVA NÃO FOI RECONHECIDA EXPRESSAMENTE NO $\S 3^{\circ}$ DO ARTIGO 226 DA CF, INEXISTINDO NORMA ESPECIIFICA.

O PRESENTE ARTIGO PRETENDE INVESTIGAR A POSIÇÃO DE MINISTROS DO STF EM RELAÇÃO AO TEMA DAS UNIÕES HOMOAFETIVAS, EM CONEXÃO COM AS FILOSOFIAS DO RECONHECIMENTO PROPOSTAS por Axel honneth e Nancy Fraser. Nesse sentido, os FUNDAMENTOS FILOSÓFICOS DAS TEORIAS DO RECONHECIMENTO PODEM SER UM INSTRUMENTAL TEÓRICO FUNDAMENTAL PARA A COMPREENSÃO DE DETERMINADAS FORMAS DE ATIVISMO JUDICIAL QUE OBJETIVAM A PROTEÇÃO DE MINORIAS ESTIGMATIZADAS CUJAS PRETENSÕES NORMATIVAS SÃO DESCONSIDERADAS PELO PROCESSO Político. PRETENDEMOS DEMONSTRAR QUE O PARADIGMa DA AUTORREALIZAÇÃO PROPOSTO POR HONNETH É IMPRECISO E INCAPAZ DE LEGITIMAR FORMAS DE ATIVISMO JUDICIAL VOLTADAS PARA A PROTEÇÃO DOS DIREITOS DAS UNIÕES HOMOAFETIVAS.

\section{PALAVRAS-CHAVE}

RECONHECIMENTO; IDENTIDADE; MINORIAS GAYS; HONNETH; FraSER.

\begin{abstract}
THE HOMOSEXUAL UNION RIGHTS ARE DEBATED AS ONE OF THE MOST CONTROVERSIAL TOPICS OF CONSTITUTIONAL LAW. IT IS KNOWN THAT THE HOMOSEXUAL UNION WAS NOT EXPLICITLY RECOGNIZED BY THE ARTICLE $226 \oint 3^{\circ} \mathrm{FROM} F C$, AS THERE IS NO SPECIFIC REGULATION FOR THIS SUBJECT. THIS PAPER INTENDS TO INVESTIGATE STF MINISTERS POSITION IN RELATION TO HOMOSEXUAL UNION ACCORDING to AXEL HONNETH AND NANCY FRASER PHILOSOPHIES OF RECOGNITION. IN THIS SENSE, THE PHILOSOPHICAL BASIS FROM RECOGNITION THEORIES MAY BE A THEORETICAL INSTRUMENT TO COMPREHEND SOME FORMS OF JUDICIAL ACTIVISM WHICH AIMS ARE TO PROTECT STIGMATIZED MINORITIES WHOSE REGULATORY INTENTIONS ARE DISREGARDED BY THE POLITICAL PROCESS. WE INTEND TO DEMONSTRATE THAT THE HONNETH'S PARADIGM OF ACHIEVEMENT IS IMPRECISE AND CAN'T LEGITIMATE FORMS OF JUDICIAL ACTIVISM AIMED TO PROTECT THE RIGHTS OF HOMOSEXUAL UNIONS.

KEYWORDS

RECOGNITION; IDENTITY; GAY MINORITIES; HONNETH; FRASER.
\end{abstract}

\section{INTRODUÇÃO}

O debate sobre os direitos das uniões homoafetivas constitui um dos temas mais interessantes do direito civil-constitucional. O $\S 3^{\circ}$ do artigo 226 da Constituição Federal não reconhece expressamente a união homoafetiva, inexistindo norma específica. A Constituição reconhece as uniões heterossexuais como sociedades de afeto, mas em relação às uniões homossexuais não há regulamentação legal. 
É importante mencionar que, para parte da doutrina, as uniões homoafetivas são meras "sociedades de fato". A affectio societatis, como atributo específico do contrato de sociedade comercial, é a disposição do contraente em participar de uma sociedade, permitindo a reunião de esforços visando ao lucro e diferenciando-se da affectio maritalis. Esta diz respeito às uniões heteroafetivas e homoafetivas, pressupondo duas pessoas que estabelecem uma comunhão de vida, de forma pública, contínua e duradoura. Os atributos constitutivos de uma e outra não se confundem, razão por que a união homoafetiva não pode ser concebida como uma "sociedade de fato", mas sim como uma sociedade de afeto.

Como resultado, parte da jurisprudência brasileira também resiste em equiparar as uniões homoafetivas às entidades familiares, impedindo a distribuição das demandas às varas de família. O presente artigo propugna analisar o recente posicionamento do SupremoTribunal Federal (STF) em relação aos direitos das uniões homoafetivas à luz das filosofias do reconhecimento propostas por Axel Honneth e Nancy Fraser. Axel Honneth desenvolveu filosofia política que enfatiza a importância das relações intersubjetivas de reconhecimento, articulando uma teoria do desenvolvimento psíquico à evolução moral da sociedade. O debate entre Honneth e Fraser, que inspirou o livro Redistribution or Recognition, é relevante para fundamentar o posicionamento específico dos ministros do STF na proteção dos direitos de casais homoafetivos. Evidentemente, existem diversas compreensões no âmbito da teoria da justiça que também poderiam elucidar o posicionamento do STF em relação ao tema das uniões homoafetivas - por exemplo, o procedimentalismo habermasiano (e sua ideia de cooriginariedade entre as autonomias pública e privada) ou a ideia de Rawls de razão pública. Não obstante, no estrito objeto do texto, propugnamos nos limitar ao debate Fraser-Honneth, pois o embate teórico entre ambos permite, por exemplo, discutir se o reconhecimento seria uma questão de justiça ou de autorrealização e contrapor a estratégia teórica dualista à monista.

O diálogo entre os autores é relevante, em primeiro lugar, pois, como pretendemos demonstrar, o conceito de invisibilidade social, que foi delineado por Honneth, constitui um instrumental teórico essencial para a compreensão de formas de judicialização voltadas para resguardar os direitos de casais homoafetivos, desde que desvinculadas de experiências de sofrimento individual. Há também uma segunda justificativa em relação à necessidade de investigarmos uma fundamentação filosófica da tutela jurisdicional à luz do debate Honneth-Fraser. Como assinala Honneth, o direito tem um papel fundamental na temática do reconhecimento na medida em que incorpora a concepção universalista de sujeitos de direito, propiciando o reconhecimento jurídico enquanto expressão da ideia de autorrespeito.

Desse modo, o debate estabelecido entre os autores sobre os fundamentos filosóficos das teorias do reconhecimento é fundamental para a compreensão da temática das uniões homoafetivas no STF, porquanto a arena jurídico-constitucional constitui um espaço privilegiado de expressão de lutas por reconhecimento por meio das quais as 
minorias sexuais reconstroem os padrões de interação social. Daí a relevância de compreendermos a evolução jurisprudencial dos direitos das uniões homoafetivas no STF à luz dos fundamentos filosóficos das teorias do reconhecimento delineados por Honneth e Fraser. Tais fundamentos filosóficos tornam-se relevantes na medida em que compreendemos a arena jurídico-constitucional como um cenário simbólico de lutas por reconhecimento. Esse cenário simbólico reflete-se nos processos morais por meio dos quais os indivíduos geram representações de sua identidade, transformando os sentimentos dos cidadãos, passando estes a delinear sentidos e interpretações constitucionais capazes de satisfazer a suas expectativas normativas.

No ensejo, o debate Honneth-Fraser também pode elucidar aspectos importantes da temática relativa à proteção judicial dos direitos de casais homoafetivos, justamente por estabelecer discussões sobre a possibilidade de superação, por meio do debate público, dos contextos de felicidade ilusória inerentes ao “escravo feliz". Por fim, a discussão sobre os limites teóricos e sobre o caráter impreciso do paradigma da autorrealização também é relevante quando se debatem temas como a criminalização da homofobia. Como se sabe, o Projeto de Lei $n^{\circ} 122 / 06$, que alterava a Lei Federal n ${ }^{\circ} 7716 / 89$ e pretendia criminalizar a homofobia, gerou protestos em junho de 2008: um ato de defesa da liberdade religiosa foi promovido por frentes parlamentares da Família e Apoio à Vida. Trata-se de um conflito constitucional entre a liberdade de manifestação de pensamento (art. $\left.5^{\circ}, \mathrm{IV}\right)$ e o livre exercício dos cultos (art. $\left.5^{\circ}, \mathrm{VI}\right)$, por um lado, e a não discriminação, por outro.

Outrossim, a principal problemática a ser enfrentada consiste no questionamento: o ideal da autorrealização pode ser considerado como um paradigma filosófico capaz de legitimar certas formas de ativismo judicial que objetivam resguardar direitos de minorias sexuais? É possível conceber o paradigma da autorrealização, inerente a contextos de vulnerabilidade moral, como fundamento filosófico capaz de garantir a legitimidade da expansão da tutela jurisdicional voltada para a proteção de minorias estigmatizadas? Nesse sentido, os fundamentos filosóficos das teorias do reconhecimento podem ser um instrumental teórico importante para a compreensão de determinadas formas de tutela judicial que objetivam a proteção de minorias estigmatizadas cujas pretensões normativas são desconsideradas pelo processo político.

Como pretendemos demonstrar, o modelo de Fraser destaca-se como um instrumental teórico relevante para legitimar formas de judicialização voltadas para a proteção de minorias sexuais, pois situa o reconhecimento na dimensão institucional e no debate público, sendo este propiciado por uma participação paritária independentemente da experiência subjetiva do indivíduo. No caso dos direitos de homossexuais, optamos pela perspectiva deontológica de Fraser, pois compreendemos que a temática do reconhecimento na jurisprudência do STF não deve ser analisada como uma questão ética, mas por meio de uma teoria moral da justiça, que é capaz de inspirar uma efetiva conscientização a respeito de um contexto de opressão. 
De um lado, propugnamos salientar, com base em Nikolas Kompridis, que a concepção formal de eticidade - desenvolvida por Honneth - não é suficientemente precisa na especificação das condições formais inerentes ao ideal da autorrealização, minimizando a pluralidade de bens das sociedades contemporâneas. De outro lado, pretendemos demonstrar, com base em Adorno e Horkheimer, que o paradigma da autorrealização, delineado por Honneth, é um instrumental teórico impreciso para legitimar formas de judicialização voltadas para a proteção dos direitos das uniões homoafetivas, pois o ideal da "participação paritária”, desenvolvido por Fraser, assim como outras teorias da justiça procedimentais, pode inspirar a atuação do STF. Por fim, propugnamos investigar a relevância da perspectiva teórica de Fraser para a compreensão de formas de judicialização capazes de desconstruir obstáculos culturais institucionalizados que impedem a participação paritária de homossexuais. Com isso, pretende-se permitir, por meio de um padrão universal e procedimental de justiça, a desnaturalização da felicidade ilusória do escravo feliz.

No momento, passamos a analisar o posicionamento dos ministros do STF em relação ao tema das uniões homoafetivas.

\section{O STF E AS UNIÕES HOMOAFETIVAS}

Recentemente, os ministros do STF, julgando a Ação Direta de Inconstitucionalidade (ADI) $n^{\circ} 4277$ e a Arguição de Descumprimento de Preceito Fundamental (ADPF) $\mathrm{n}^{\circ} 132$, reconheceram a união estável homoafetiva por unanimidade. A ADPF $\mathrm{n}^{\circ} 132$, proposta pelo governador do Rio de Janeiro, Sérgio Cabral, tratava dos direitos previdenciários de uniões homoafetivas, pleiteando a aplicação do regime jurídico das uniões estáveis às uniões homoafetivas de funcionários públicos civis em todo o país. De um lado, a ADPF n ${ }^{\circ} 132$ postulava a aplicação da técnica de interpretação conforme à Constituição aos artigos 19, II e V, e 33 do Decreto-Lei no 220/75, negando qualquer interpretação que desqualificasse a união estável de servidores homoafetivos relativamente à proteção jurídica da união estável de servidores heterossexuais. De outro lado, aduziu que o não reconhecimento da união homoafetiva afrontava princípios como igualdade, liberdade e dignidade da pessoa humana, previstos na Constituição.

Diante dessa estrutura conceitual, a ADI n ${ }^{\circ} 4277$, por sua vez, foi ajuizada inicialmente no STF como ADPF $n^{\circ} 178$, requerendo o reconhecimento da união estável homoafetiva como entidade familiar à qual seriam atribuídos os mesmos direitos e deveres dos companheiros das uniões estáveis. Ambas as ações pretendiam a interpretação do artigo 1723 do Código Civil conforme à Constituição. O relator, ministro Carlos Ayres de Brito aduziu em seu voto que "o sexo das pessoas, salvo expressa disposição constitucional em contrário, não se presta como fator de desigualação jurídica” (BRASIL, 2011a). O tratamento discriminatório ou preconceituoso em razão do sexo 
dos seres humanos confrontava com o objetivo constitucional de promover o bem de todos. Afirmou a centralidade do pluralismo sócio-político cultural, sendo este um valor do preâmbulo da Constituição e um dos fundamentos da República Federativa do Brasil (art. $\left.1^{\circ}, \mathrm{V}\right)$.

Nesse particular, o pluralismo "serve de elemento conceitual da própria democracia material ou de substância, desde que se inclua no conceito de democracia dita substancialista a respeitosa convivência dos contrários” (BRASIL, 2011a). Para o ministro relator, o preconceito em razão do sexo seria vedado constitucionalmente, uma vez que a Constituição não obrigou nem proibiu o uso concreto da sexualidade humana. Seria um direito fundamental do indivíduo a liberdade de dispor da própria sexualidade, enquanto expressão da autonomia da vontade, além de cláusula pétrea.

Dessa maneira, de acordo com o ministro Carlos Ayres de Britto, a formação da família não se encontra atrelada ao requisito da heteroafetividade nem a qualquer formalidade cartorária, celebração civil ou liturgia religiosa. Nas suas palavras, "o núcleo familiar seria o principal lócus de concreção de direitos fundamentais que a própria Constituição designa por intimidade e vida privada (inciso X do art. $5^{\circ}$ ), além de, já numa dimensão de moradia, se constituir no asilo inviolável do indivíduo”. E conclui: “a família é, por natureza ou no plano dos fatos, vocacionalmente amorosa, parental e protetora dos respectivos membros, constituindo-se, no espaço ideal das mais duradouras, afetivas, solidárias ou espiritualizadas relações humanas de índole privada” (BRASIL, 2011a).

É premente lecionar que o ministro Luiz Fux, por sua vez, também delineou uma interpretação substantiva e principiológica do conceito de família com base em uma compreensão constitucional desta que a concebe em uma perspectiva instrumental voltada para a proteção dos direitos fundamentais. É clara a assertiva do Min. Luiz Fux:

... Bem ao contrário, a Constituição de 1988 consagrou a família como instrumento de proteção da dignidade dos seus integrantes e do livre exercício de seus direitos fundamentais, de modo que, independentemente de sua formação - quantitativa ou qualitativa - serve o instituto como meio de desenvolvimento e garantia da existência livre e autônoma dos seus membros. (BRASIL, 2011b).

Nesse contexto, os ministros Celso de Mello, Cesar Peluso Gilmar Mendes, Joaquim Barbosa, Luiz Fux, Marco Aurélio de Mello e Ricardo Lewandowsky e as ministras Carmem Lucia Antunes Rocha e Ellen Gracie acompanharam o voto do ministro relator no sentido da procedência no julgamento do pedido com efeito vinculante, conferindo interpretação conforme à Constituição para excluir qualquer interpretação do artigo 1723 do Código Civil que inviabilizasse o reconhecimento da união homoafetiva como entidade familiar. 
Antes do referido julgamento, não havia uma posição do STF sobre a possibilidade jurídica das uniões estáveis homoafetivas, uma vez que o órgão pleno não havia apreciado nenhuma ação direta de inconstitucionalidade ou ação declaratória de constitucionalidade. Três ministros, entretanto, haviam se manifestado sobre a questão, assumindo relevância a decisão monocrática do ministro Celso de Mello na ADI $\mathrm{n}^{\mathrm{o}} 3.300 / \mathrm{DF}$. Igualmente posicionaram-se os ministros Gilmar Mendes, no julgamento do RESP eleitoral $n^{\circ} 24.564$, quando exercia a função de ministro do TSE, e Eros Grau, no julgamento do Recurso Extraordinário nº 406.837/SP.

Nessa trajetória jurídica, destacou-se a postura maximalista do ministro Celso de Mello no julgamento da ADI n ${ }^{\circ} 3.300 / \mathrm{DF}$, impetrada por associações de defesa dos direitos dos homossexuais contra o artigo $1^{\circ}$ da Lei $n^{\circ} 9278 / 96$, no que se refere à expressão "o homem e a mulher", requerendo a declaração de inconstitucionalidade parcial do dispositivo, por contrariar o princípio da igualdade, visando declarar a existência da união estável homoafetiva.

Assim, a decisão do ministro Celso de Mello no julgamento da ADI no 3.300/DF assumiu especial relevância na construção de uma cultura constitucional inclusiva, uma vez que, não obstante tenha extinguido o processo, sem resolução do mérito (tendo em vista a derrogação da Lei n ${ }^{\circ}$ 9.278/96 pelos artigos 1722 a 1727 do Código Civil de 2002), terminou por manifestar-se sobre este. Indubitavelmente, tal decisão, ao pretender a qualificação normativa das uniões homoafetivas como entidades familiares, assumiu uma dimensão pedagógica. É clara a assertiva do ministro Celso de Mello:

... Quanto à tese sustentada pelas entidades autoras de que o magistério da doutrina, apoiando-se em valiosa hermenêutica construtiva, utilizando-se da analogia e invocando princípios fundamentais (como os da dignidade da pessoa humana, da liberdade, da autodeterminação, da igualdade, do pluralismo, da intimidade, da não-discriminação e da busca da felicidade), tem revelado admirável percepção do alto significado de que se revestem tanto o reconhecimento do direito personalíssimo à orientação sexual, de um lado, quanto à proclamação da legitimidade ético-jurídica da união homoafetiva como entidade familiar, de outro, em ordem a permitir que se extraiam, em favor de parceiros homossexuais, relevantes consequências no plano do Direito e na esfera das relações sociais (BRASIL, 2006b).

Em suma, ao assumir uma metodologia principiológica e substantiva, posicionou-se em favor da possibilidade jurídica da união estável homoafetiva, resgatando os princípios da dignidade da pessoa humana, da liberdade, da autodeterminação, da igualdade, do pluralismo, da não discriminação e da busca da felicidade, prestigiando decisões do Tribunal de Justiça do Rio Grande do Sul (relativamente às uniões 
homoafetivas), nas quais assumem relevância julgados juridicamente sensíveis à temática dos direitos de casais homoafetivos.

Nesse cenário, analisando o tema, Luis Roberto Barroso sublinha que:

... a Constituição teria reconhecido expressamente três tipos de família: a decorrente de casamento (artigo 226, $\S 1^{\circ}$ e $2^{\circ}$ ); a decorrente de união estável entre pessoas de sexos diferentes (artigo 226 , $\S 3^{\circ}$ ); e a família monoparental, ou seja, aquela formada por um dos dois pais e seus descendentes (artigo 226, $\S 4^{\circ}$ ) (Barroso, 2007, p. 37).

Para o autor, o reconhecimento da união homoafetiva seria decorrente de uma interpretação sistemática da ordem jurídica e do reconhecimento dos elementos essenciais que caracterizam as uniões estáveis e as entidades familiares.

No que se refere aos tribunais de Justiça de segundo grau, destaca-se a jurisprudência do Tribunal de Justiça do Rio Grande do Sul, por contemplar julgados emancipatórios na ampliação dos direitos dos casais homoafetivos, influenciando o posicionamento dos ministros do Supremo Tribunal Federal. Nessa trajetória jurídico-normativa, foram as decisões do Tribunal de Justiça do Rio Grande do Sul que inauguraram um novo horizonte jurídico sensível ao reconhecimento das uniões homoafetivas como entidades familiares. A $8^{\text {a }}$ Câmara Cível do Tribunal de Justiça do Rio Grande do Sul, por meio de uma metodologia principiológica - baseada no resgate do princípio da não discriminação por orientação sexual - fixou, em 1999, a competência da Vara de Família. O argumento fundamental baseou-se no fato de que o $\S 3^{\circ}$ do artigo 226 da Constituição não obsta o reconhecimento da união homoafetiva como entidade familiar. Nas palavras da desembargadora Maria Berenice Dias, "a partir de tal posicionamento jurisprudencial, todas as ações envolvendo o relacionamento entre pessoas do mesmo sexo, ao menos no Rio Grande do Sul, migraram das varas cíveis para as varas de família” (Dias, 2006, p. 134).

Com efeito, Luis Roberto Barroso, por sua vez, postula que "a referência a homem e mulher não traduz uma vedação da extensão do mesmo regime às uniões homoafetivas" (Barroso, 2007, p. 34). Na sua percepção, o artigo 226, § 3º é uma norma inclusiva e de inspiração antidiscriminatória, pois pretende pôr fim à anterior discriminação às uniões extramatrimoniais, não devendo ser interpretada de forma discriminatória, inviabilizando a aplicação do regime da união estável às relações homoafetivas. (ibidem, p. 40). Ora, o fato de não haver uma regulamentação legal em relação à união homoafetiva na Constituição e Código Civil não implica uma vedação implícita. Nessa linha de raciocínio, o $\S 3^{\circ}$ do artigo 226, enquanto norma de inclusão, não deve inspirar uma interpretação discriminatória.

É precisamente em relação à concessão de direitos previdenciários e sucessórios que a equiparação legal à união estável revela-se fundamental. Em 2001, foi reconhecida a 
concessão da meação do patrimônio ao companheiro sobrevivente pela $7^{a}$ Câmara do Tribunal de Justiça do Rio Grande do Sul, passando a considerar, pela primeira vez, a união homoafetiva como entidade familiar. Vale a pena transcrever a ementa do julgado:

... União homossexual. Reconhecimento. Partilha do patrimônio. Meação. Paradigma. Não se permite mais o farisaísmo de desconhecer a existência de uniões entre pessoas do mesmo sexo e a produção de efeitos jurídicos derivados dessas relações homoafetivas. Embora permeadas de preconceitos, são realidades que o Judiciário não pode ignorar, mesmo em sua natural atividade retardatária. Nelas remanescem conseqüências semelhantes às que vigoram nas relações de afeto, buscando-se sempre a aplicação da analogia e dos princípios gerais do direito, revelados sempre os princípios constitucionais da dignidade humana e da igualdade. Desta forma, o patrimônio havido na constância do relacionamento deve ser partilhado como na união estável, paradigma supletivo onde se debruça a melhor hermenêutica. Apelação provida, em parte, por maioria, para assegurar a divisão do acervo entre os parceiros (RIO GRANDE DO SUL, 2001).

Em síntese, de acordo com a desembargadora Maria Berenice Dias, tratou-se de uma decisão paradigmática, que suscitou avanços relevantes na jurisprudência. Nas palavras da autora, "o Relator, ainda que não reconhecendo a existência de uma união estável, invocou, por analogia, a legislação que rege as uniões extramatrimoniais” (Dias, 2006, p. 136). Em suma, em relação ao patrimônio adquirido pelo esforço comum, foi aplicado o regime da comunhão parcial. A partir deste julgado, surgem inúmeras decisões que passam a equiparar a união entre pessoas do mesmo sexo à união estável homoafetiva.

Em face dessa leitura, a tendência majoritária da jurisprudência nacional é deferir a partilha do patrimônio adquirido pelo esforço comum, considerando inadmissível a atribuição de direitos sucessórios. A primeira decisão concedendo direitos sucessórios ao companheiro ocorreu na Justiça do Rio Grande do Sul, que considerou que o elemento afetivo determinaria a aplicação analógica com a legislação que rege a união estável. Um caso relevante foi a disputa de direitos sucessórios entre companheiro sobrevivente e municipalidade. A herança estava para ser declarada vacante e, portanto, seria atribuída ao município, tendo em vista a ausência de parentes sucessíveis, mas a decisão terminou por afastar a declaração de vacância. É oportuno transcrever o julgado:

\section{... UNIÃO ESTÁ VEL HOMOAFETIVA. DIREITO SUCESSÓRIO.}

ANALOGIA. Incontrovertida a convivência duradoura, pública e contínua entre parceiros do mesmo sexo, impositivo que seja reconhecida a existência 
de uma união estável, assegurando ao companheiro sobrevivente a totalidade do acervo hereditário, afastada a declaração de vacância da herança. A omissão do constituinte e do legislador em reconhecer efeitos jurídicos às uniões homoafetivas impõe que a Justiça colmate a lacuna legal fazendo uso da analogia. O elo afetivo que identifica as entidades familiares impõe seja feita analogia com a união estável, que se encontra devidamente regulamentada (TJRS. 4ª G.C. Cív. EI 70003967676 - Redatora para acórdão, Desa. Maria Berenice Dias, j. 9/5/2003). (Rio Grande do Sul, 2003).

Disso se infere, a nosso ver, que o caso possui uma singularidade: a inexistência de acréscimo patrimonial durante o período de convivência, pois todos os bens eram de propriedade do de cujus, adquiridos antes do início do relacionamento. $\mathrm{O} 3^{\circ}$ vicepresidente, ao proferir o voto de Minerva, concedeu ao companheiro a totalidade do acervo patrimonial do de cujus. Não podem ser consideradas, portanto, emancipatórias as tutela judiciais que se restringem à concessão da meação do companheiro, pois tal instituto é concedido por meio do recurso à sociedade de fato.

Nesse quadro teórico, é imperioso investigar que o ministro Gilmar Mendes manifestou-se sobre o tema das uniões homoafetivas no julgamento do RESP eleitoral $n^{\circ} 24.564$. A discussão jurídica surge de uma questão que pretendia indagar se a regra da inelegibilidade, que é prevista no $\S 7^{\circ}$ do artigo 14 da Constituição, aplicarse-ia às uniões homoafetivas. O registro de candidatura de companheira homoafetiva de uma deputada de Viseu (PA) foi impugnado pelo juiz eleitoral, sob o argumento da existência de união estável, o que violaria o $\S 7^{\circ}$ do artigo 14 da Constituição Federal, que proíbe a perpetuação de grupos familiares no poder executivo, tendo em vista a vedação da candidatura dos cônjuges dos ocupantes dos cargos de presidente da República, governador e prefeito.

Nessa perspectiva, o TRE, no julgamento do recurso interposto, deu-lhe provimento, considerando que as relações homoafetivas, não se enquadrando no conceito de união estável, não seriam contempladas pela regra da inelegibilidade. Contra tal julgamento, foi interposto o RESP eleitoral $n^{\circ} 24.564$ para o TSE, que, por intermédio do ministro relator Gilmar Mendes, aplicou a regra da inelegibilidade à candidata, uma vez que sua companheira deveria ter se licenciado seis meses antes da data da eleição, evitando o continuísmo de oligarquias no poder. É oportuno transcrever a ementa:

... Registro de candidato. Candidata ao cargo de prefeito. Relação estável homossexual com a prefeita reeleita no município. Inelegibilidade. Art 14 $\S 7^{\circ}$, da Constituição Federal. Os sujeitos de uma relação estável homossexual, à semelhança do que ocorre com os de relação estável, de concubinato e de casamento, submetem-se à regra da inelegibilidade 
prevista no art. $14 \S 7^{\circ}$ da Constituição Federal. Recurso a que se dá provimento (BRASIL, 2004).

Diante do exposto, depreende-se que o ministro Gilmar Mendes, embora não tenha expressamente reconhecido o status jurídico familiar das uniões homoafetivas, reconheceu-o implicitamente. Se a legislação eleitoral impõe obrigações jurídicas às uniões homoafetivas, não se pode deixar também de atribuir direitos a estas por meio do reconhecimento do status jurídico-familiar dessas uniões. Diante dessa estrutura conceitual, o ministro Eros Grau, no julgamento do Recurso Extraordinário no 406.837, posicionou-se sobre a temática dos direitos das uniões homoafetivas. Nesse caso, o recorrente, objetivando a equiparação ao regime da união estável, invocou o princípio da igualdade, contrapondo-se à decisão do tribunal, que compreendeu que tal regime só seria aplicável à relação homem e mulher. Como não houve a satisfação do cumprimento do requisito do prequestionamento, o ministro Eros Grau não conheceu o recurso, mas terminou por expressar implicitamente seu entendimento acerca do tema, defendendo que o regime jurídico da união estável seria inaplicável às uniões homoafetivas. Confirase o argumento do ministro:

... Insubsistente, também, a pretensão de ver aplicada à hipótese destes autos - pagamento de pensão estatutária em virtude de união homossexual - o disposto no art $226 \S 3^{\circ}$ da Constituição Federal do Brasil. Este preceito, embora represente avanço na esfera do direito social, somente reconhece como entidade familiar, para efeito de proteção do Estado, a união estável entre o homem e a mulher, desde que entre esses não se verifique nenhum impedimento legal à conversão dessa união em casamento (BRASIL, 2005).

Portanto, com base no artigo $21 \S 3^{\circ}$ do Regimento Interno do STF, foi reconhecida a ausência de prequestionamento explícito, conduzindo ao não seguimento do recurso. E, embora não se posicionando expressamente sobre a questão relativa à violação ao princípio da isonomia, terminou por expressar o seu posicionamento. Defendeu que o regime jurídico da união estável não poderia ser aplicado analogicamente à união homoafetiva, mas apenas à união entre homem e mulher.

No ensejo, o STF, a partir do deferimento de liminar de âmbito nacional pelo ministro Marco Aurélio de Mello, o INSS passou a considerar o companheiro ou a companheira homossexual como dependente preferencial, deferindo também o processamento dos pedidos de pensão por morte e de auxílio-reclusão realizados por companheiro do mesmo sexo, cumpridos os requisitos legais aplicados aos casais heterossexuais (artigos 74 a 80 da Lei $n^{\circ} 8213 / 91$ ). (BRASIL, 2003).

É nesse contexto que foi ajuizada, em 2008, a ADPF nº 132 no STF pelo governador do Rio de Janeiro, Sérgio Cabral, postulando a extensão de direitos previdenciários 
para parceiros do mesmo sexo que vivem uma união homoafetiva. O governador fluminense requereu a equiparação legal do regime das uniões estáveis, previsto no artigo 1.723 do Código Civil, às uniões homoafetivas de funcionários públicos civis de todo o país. Nessa configuração normativa, em 2009, foi ajuizada a ADPF n 178 no STF pela procuradora-geral da República, Déborah Duprat, pretendendo a equiparação das uniões entre pessoas do mesmo sexo às uniões estáveis, observando-se os pressupostos legais. Defende que:

... se deve extrair diretamente da Constituição de 1988, notadamente dos princípios da dignidade humana (art. $1^{\circ}$, inciso III), da igualdade (art. $5^{\circ}$, caput), da vedação de discriminações odiosas (art. $3^{\circ}$, caput), da liberdade (art. $5^{\circ}$, caput) e da proteção à segurança jurídica, a obrigatoriedade do reconhecimento da união entre pessoas do mesmo sexo como entidade familiar (BRASIL, 2011c).

Sob esse aspecto, percebemos que o Judiciário pode funcionar como caixa de ressonância em relação às pretensões normativas de certos grupos. Indiscutível a atuação efetiva do Supremo Tribunal Federal, enquanto instância de representação de minorias. Indubitavelmente, tal postura ativista do Judiciário na proteção de minorias insere-se dentro do fenômeno denominado "neoconstitucionalismo", concebido como um complexo de transformações suscitadas no direito constitucional europeu após a Segunda Guerra, que foram capazes de transformar o papel da Constituição nas instituições contemporâneas. A dimensão do constitucionalismo e a da democracia passam a articular-se de forma indissociável no estado democrático de direito, permitindo um novo relacionamento entre direito e moral. Os paradigmas normativos no processo de reconstitucionalização do direito são a Lei Fundamental de Bonn e a criação do Tribunal Constitucional Federal. Após a Segunda Guerra, deixa de prevalecer na Europa o modelo de supremacia do parlamento, predominando o da supremacia da Constituição, com a criação de tribunais constitucionais que passaram a resguardá-la inclusive contra a vontade majoritária, podendo recorrer a argumentos morais.

É premente salientar que os posicionamentos dos ministros Celso de Mello, Gilmar Mendes e Marco Aurélio de Mello assumiram especial relevância na construção de uma cultura constitucional capaz de superar quadros de "invisibilidade social" de grupos estigmatizados. Nesse particular, é necessário elucidar os fundamentos filosóficos das teorias do reconhecimento de Axel Honneth e Nancy Fraser.

\section{Algumas reflexões sobre o debate Honneth-Fraser e SuA relaçÃo COM O TEMA DAS UNIÕES HOMOAFETIVAS}

De início, é mister sublinhar que Axel Honneth, seguindo a tradição hegeliana, enfatiza 
a centralidade das lutas intersubjetivas por reconhecimento mútuo na autorrealização dos indivíduos. Se a identidade dos indivíduos delineia-se por meio da intersubjetividade, é possível estabelecer três formas de interação social. A autoconfiança é a primeira forma de interação social, sendo fundamental na constituição da personalidade do indivíduo, pois decorre das relações de amor e amizade. Com base em Winnicott, Honneth analisa a relação conflitiva entre mãe e filho, de forma que a unidade originalmente simbiótica torna-se suscetível a transformações, originando uma relação de dependência relativa, ou seja, uma instância de autonomia apoiada pela dedicação materna. A segunda forma de interação social é o autorrespeito.

Por meio da atribuição de princípios morais universalistas consagrados nos sistemas jurídicos, os indivíduos constroem sua autoimagem, alcançando a ideia de autorrespeito. Por fim, a dimensão da autoestima constitui a terceira forma de interação social que conduz ao reconhecimento, porquanto os indivíduos tornam-se socialmente estimados em razão de suas características e realizações no âmbito da divisão do trabalho de uma comunidade específica (Bunchaft, 2009, p. 378-379). Nas palavras de Honneth, para alcançarem uma autorrelação bem-sucedida, os sujeitos humanos precisam, "além da experiência da dedicação afetiva e do reconhecimento jurídico, de uma estima social que lhes permita referir-se positivamente a suas propriedades e capacidades concretas" (Honneth, 2003a, p. 198). A ideia fundamental é a centralidade da dimensão ética da injustiça, inspirando recursos teóricos capazes de renovar a teoria crítica. Para Honneth, somente por meio do conflito social, que é motivado pelos padrões concretos de desrespeito, é possível rearticular os padrões de interação social. É oportuno resgatar uma passagem que elucida o pensamento do autor:

... Para chegar a uma autorrelação bem-sucedida, ele depende do reconhecimento intersubjetivo de suas capacidades e de suas realizações; se uma tal forma de assentimento social não ocorre em alguma etapa de seu desenvolvimento, abre-se na personalidade como que uma lacuna psíquica, na qual entram as reações emocionais negativas como a vergonha ou a ira. Daí a experiência do desrespeito estar sempre acompanhada de sentimentos afetivos que, em princípio, podem revelar ao indivíduo que determinadas formas de reconhecimento lhe são socialmente denegadas (Honneth, 2003a, p. 220).

Nessa concepção filosófica, Honneth resgata o pensamento de Dewey, que concebe os sentimentos como "a repercussão afetiva do sucesso ou insucesso de nossas intenções práticas.” (ibidem, p. 221). Desse modo, o filósofo alemão investiga as situações de vulnerabilidade moral e as experiências concretas de desrespeito, que surgem quando nossos parceiros de interação, não atendendo a nossas expectativas normativas, vivenciam sentimentos de vexação, que "consistem num rebaixamento 
do sentimento de valor próprio”. (ibidem, p. 222). Não obstante, o autor delineia um instrumental teórico relevante para atender aos desafios propostos por contextos de opressão na sociedade: o conceito de invisibilidade social. Para Honneth, "sujeitos humanos são visíveis a outro sujeito, na medida em que este pode identificá-los, de acordo com as características do relacionamento, como pessoas claramente definidas por propriedades" (Honneth, 2001a, p. 2). Nas palavras do autor, "a história cultural oferece inúmeros exemplos nos quais o dominador expressa sua superioridade social ao não perceber aqueles que eles dominam” (ibidem, p. 1). Um sujeito pode confirmar sua própria visibilidade somente forçando seu parceiro de interação social a reconhecer suas singularidades e propriedades que formam uma identidade.

Outrossim, Honneth, em sua descrição acerca da luta por reconhecimento, apresenta-nos uma concepção formal do conceito de eticidade hegeliana. O filósofo pretende articular elementos da tradição kantiana e aristotélica de forma bastante original, combinando instâncias concretas de reconhecimento com características universais ínsitas a qualquer forma social capaz de propiciar a efetividade dos pressupostos para uma autorrealização plena. A sua teoria do reconhecimento oscila entre o liberalismo e o comunitarismo, incorporando elementos de ambas as tradições, pretendendo o universalismo kantiano no que se refere à autonomia moral, mas articulando-o à adesão social e à intersubjetividade hegeliana. É premente enfatizar que, em relação à tradição kantiana, o conceito de respeito moral é decorrente do imperativo categórico, que pretende tratar cada indivíduo como um fim em si mesmo; entretanto, tal princípio, para Honneth, só encontra efetividade em instâncias concretas de reconhecimento, expressas em termos de processos intersubjetivos por reconhecimento mútuo.

Em Sofrimento de indeterminação, Honneth delineia uma atualização da filosofia do direito hegeliana, resgatando o conceito de espírito objetivo, pois deduz os princípios universais de justiça com base no contexto social, tendo em vista a especificação da razão nas instituições e nas práticas sociais (Honneth, 2007c). A primeira parte do livro representa uma releitura das construções teóricas do jovem Hegel, que pretende delinear um enfoque intersubjetivo das lutas por reconhecimento. Para Hegel, existem três esferas diferenciadas de reconhecimento: no amor, no direito e na solidariedade social. Honneth, entretanto, encontra alguns obstáculos teóricos na filosofia hegeliana, como a institucionalização excessiva das esferas sociais a partir do poder estatal, minimizando a contribuição participativa dos indivíduos na construção dessa esfera. A solução para tal dilema teórico, para Honneth, seria a adoção do critério da amizade como parâmetro para uma esfera ética. A inovação teórica de Honneth consiste em afirmar a centralidade da concepção de amizade como elemento fundamental da dimensão da eticidade.

No ensejo, como salienta Honneth, "pode realmente ser plausível falar em direitos universais e deveres em relação ao reconhecimento da autonomia moral de todos 
seres humanos; entretanto tal formulação seria fortemente apropriada para formas de reconhecimento associadas com o cuidado e a estima" (Honneth, 2007b, p. 130131). Nesse sentido, a autonomia moral do sujeito somente se cristaliza em uma sociedade que propicia concretamente o reconhecimento aos indivíduos nas três esferas: do amor, dos direitos e da solidariedade. Honneth estabelece uma condição formal de eticidade, sem apelar para concepções substantivas de bem, o que nos leva a indagar: como demonstrar a universalidade do ideal de autorrealização sem minar sua normatividade?

Assim, o filósofo apresenta uma resposta para tal indagação, considerando o ideal da autorrealização como o mais importante dos bens humanos. Kompridis, entretanto, postula que "Honneth é decididamente vago em relação ao que efetivamente significa autorrealização. Uma vez que ele se interessa apenas em especificar as condições formais da autorrealização, não qualquer concepção específica de autorrealização, sua imprecisão é deliberada” (Kompridis, 2004, p. 334). Nesse cenário, de um lado, entendemos que o filósofo é incapaz de se contrapor ao argumento segundo o qual tal concepção formal de eticidade pressupõe e é delineada por uma própria concepção particular de bem.

De outro lado, surge a questão: será que a concepção universalista de bem se sustenta em um contexto de variabilidade histórica e cultural das concepções de bem? O conteúdo das concepções de vida boa não é mais complexo e multifacetado que a sua concepção formal de eticidade? Não haveria uma pluralidade de bens, que muitas vezes caminham em direções opostas? Com efeito, compartilhamos com Kompridis o entendimento segundo o qual o estabelecimento de uma distinção entre forma e conteúdo da concepção de bem é absolutamente incompatível com o seu caráter contingente e mutável.

Nessa linha de raciocínio, os desenvolvimentos teóricos de Honneth têm sido confrontados com a perspectiva de Nancy Fraser, sendo tal embate teórico consagrado no livro Redistribution or Recognition. A divergência entre os autores surge porque, para Fraser, a realização da justiça demanda políticas tanto de redistribuição como de reconhecimento. A autora pretende integrar ao reconhecimento cultural políticas econômicas redistributivas voltadas para a redução das diferenças sociais. Tal reconhecimento é estabelecido a partir de uma perspectiva desconstrutivista, que implicaria não a afirmação essencializada da identidade de grupo, mas a desconstrução desta. Em se tratando de classes sociais nas quais os indivíduos são tradicionalmente explorados, entretanto, são necessários remédios redistributivos que visam superar injustiças econômicas.

A autora procura romper com a desvinculação entre as dimensões econômica e cultural, superando a visão dicotômica que afirma a centralidade das questões distributivas ou se restringe às injustiças culturais. A divisão social entre homossexuais e heterossexuais, por exemplo, é estabelecida tendo por base não apenas parâmetros 
econômicos, pois os homossexuais, situando-se nas mais diversas posições sociais, não podem ser considerados como uma classe explorada. Nas palavras de Fraser, "a divisão é enraizada, diferentemente, na ordem de status da sociedade como padrões institucionalizados de valores culturais que constroem a heterossexualidade como natural e normativa e a homossexualidade como perversa e desprezada" (Fraser, 2003a, p. 18). Em síntese, o não reconhecimento não é delineado em termos de depreciação da identidade, mas como uma subordinação institucionalizada nas diversas áreas do direito relativas à família, à intimidade e à igualdade. É relevante trazer as palavras de Fraser:

... Eles estão também estabelecidos em muitas áreas da política governamental (incluindo imigração, naturalização e política de asilo) e padrões de práticas profissionais (incluindo medicina e psicoterapia). Padrões valorativos heteronormativos também penetram na cultura popular e na interação cotidiana. O resultado é construir gays e lésbicas como uma sexualidade desprezada, sujeitos a formas sexualmente específicas de subordinação de status. O último inclui vergonha e assalto, exclusão dos direitos e privilégios do casamento e parentesco, restrições nos direitos de expressão e associação, imagens estereotipadas danosas na mídia, assédio e depreciação na vida cotidiana e negação dos plenos direitos e de igual proteção da cidadania (ibidem, p. 18).

Disso se infere que gays e lésbicas também são submetidos a injustiças decorrentes da subordinação na ordem de status, com reflexos na dimensão econômica, haja vista a institucionalização de normas heterossexistas que inviabilizam os benefícios sociais e familiares concedidos às relações heterossexuais. Nas palavras da autora, "superar a homofobia e o heterossexismo exige a mudança da ordem sexual de status, desinstitucionalizando padrões valorativos heteronormativos e substituindo-os por padrões que expressem igual respeito por gays e lésbicas.” (ibidem, p. 19). Nesse quadro teórico, a discriminação contra as mulheres, por sua vez, articula elementos de exploração econômica com aspectos de discriminação sexual, em uma perspectiva bidimensional, seja na esfera econômica, seja na esfera do reconhecimento. A discriminação de gênero pressupõe a injustiça na economia e na ordem de status na sociedade, pois a divisão fundamental entre trabalho produtivo remunerado ocupado por homens e trabalho doméstico não remunerado atribuído às mulheres é construída com base na categoria do gênero.

Honneth, por sua vez, desenvolve uma abordagem monista em relação às diferentes formas de injustiça, que passam a ser consideradas como experiências de invisibilidade social ou de não reconhecimento. Indubitavelmente, o modelo de status de Fraser pretende contrapor-se ao modelo teórico delineado por Honneth, porquanto as 
políticas identitárias - ao focalizarem a perspectiva da autorrealização - negligenciam os padrões institucionalizados de desvalorização cultural que impedem os indivíduos de se tornarem parceiros plenos na esfera da participação paritária. A ideia é desconstruir "leis matrimoniais que excluem parceiros do mesmo sexo como ilegítimos e perversos, políticas de bem-estar social que estigmatizam mães-solteiras como parasitas sexualmente irresponsáveis, e práticas policiais tais como os perfis raciais que associam pessoas racializadas à criminalidade" (Fraser, 2003a, p. 29-30). Nesse contexto, Fraser focaliza não as concepções de vida boa, mas a desinstitucionalização dos padrões de valores culturais que impedem a participação paritária do indivíduo, enquanto parceiro pleno da vida social. Para Honneth, a privação de direitos a minorias sexuais se expressa por meio de uma experiência de desrespeito, que conduz à perda do autorrespeito e da capacidade de referir-se a si mesmo como um igual dentro da interação social. Fraser, por sua vez, sublinha que a questão fundamental não é focalizar as experiências de sofrimento decorrentes de contextos de vulnerabilidade moral, como pretende Honneth, mas as efetivas implicações do não reconhecimento na esfera da participação paritária.

Diante dessa estrutura conceitual, “o modelo de status é deontológico e não sectário", pois “não apela para uma concepção de autorrealização ou bem. Diferentemente, apela para uma concepção de justiça que pode - e deve - ser aceita por aqueles com concepções divergentes de bem” (ibidem, p. 31). A ideia é desvincular-se de demandas de reconhecimento identitárias atinentes a concepções de autorrealização, que inspirariam uma postura sectária.

Nessa perspectiva, optamos pelo modelo teórico de Nancy Fraser na estratégia de legitimação de formas de atuação judicial visando a resguardar direitos de casais homoafetivos. Tal estratégia deve voltar-se para a eliminação dos valores culturais institucionalizados que impedem as minorias sexuais de interagirem na vida social, inviabilizando a participação paritária. Mas, para Honneth, a força motriz das experiências de resistência social surge das experiências de desrespeito que levam os indivíduos a se articularem em lutas sociais por reconhecimento. É premente explicitar, entretanto, que o paradigma da autorrealização não pode ser considerado como um instrumental filosófico capaz de legitimar de maneira precisa formas específicas de judicialização expressas na jurisprudência do STF - voltadas para tutelar direitos fundamentais de homossexuais, pois se torna incapaz de solucionar contextos em que há uma falta de consciência da própria situação de infelicidade. Sob esse aspecto, o pensamento de dois autores da Escola de Frankfurt, Horkheimer e Adorno, assume relevância. Esses autores defendiam a ideia de que a sociedade industrial poderia inspirar um controle social na cultura de massas, impedindo que os indivíduos se conscientizassem de uma situação de frustração e opressão. Nesse particular, a indústria cultural poderia inspirar um controle social tão potente que impediria seus membros de formarem desejos não facilmente realizáveis, resultando uma sociedade de escravos felizes. 
Desse modo, apesar de todo o progresso alcançado pela humanidade a partir do Iluminismo, este não foi capaz de ensejar a emancipação humana, uma vez que os mecanismos tecnológicos inerentes à indústria cultural objetivavam alcançar a satisfação das necessidades de desenvolvimento do capitalismo. Nas palavras dos autores,

O princípio básico consiste em lhes apresentar, tanto as necessidades, como tais, que podem ser satisfeitas pela indústria cultural, quanto em, por outro lado, antecipadamente, organizar essas necessidades de modo que o consumidor a elas se prenda, sempre e tão só como eterno consumidor, como objeto da indústria cultural (Adorno e Horkheimer, 1985, p. 180).

Assim, a função primordial da teoria crítica deveria ser fornecer um instrumental filosófico capaz de permitir que os indivíduos, ao tomarem consciência da sua própria situação de frustração, desconstruam os mecanismos institucionais que conduzem à subordinação.

Nesse sentido, a falta de consciência de uma situação de infelicidade não pode ser superada por uma teoria que afirma a centralidade das experiências de desrespeito e humilhação como base motivacional das lutas sociais. E se o escravo feliz não sofre, vivenciando um contexto de felicidade ilusória? Nesse ponto, o paradigma da autorrealização revela-se impreciso para uma efetiva conscientização de uma situação de opressão, sendo insuscetível de legitimar qualquer tipo de tutela jurisdicional direcionada a resguardar direitos de casais homoafetivos. Em síntese, na nossa percepção, o STF, ao resguardar certos direitos de casais homoafetivos, pode desconstruir, com base na ideia de justiça, obstáculos institucionais que impedem a participação paritária de minorias sexuais; entretanto, não pode garantir positivamente a autorrealização desses grupos.

Muitas vezes, a promoção da autorrealização de determinados indivíduos pode incrementar experiências de sofrimento e humilhação de outros. A questão relativa à incerteza ou à imprecisão conceitual inerente ao ideal da autorrealização é relevante, pois o Senado aprovou requerimento apresentado por Marta Suplicy para desarquivar o Projeto de Lei da Câmara (PLC) n ${ }^{\circ} 122$, que pretende criminalizar a homofobia. Como se sabe, na Carta em Favor da Liberdade de Expressão, Liberdade Religiosa e contra a Pedofilia, que foi entregue ao Senado em 2008, alegou-se que o projeto deveria ser rejeitado, pois traria consequências nefastas para a liberdade religiosa e a liberdade de expressão garantidas constitucionalmente. No momento, Marta Suplicy tenta aprovar no Senado um substitutivo ao PLC n ${ }^{\circ} 122$, incorporando uma mudança no artigo 20, no que se refere à liberdade de expressão. O artigo $3^{\circ}$ do substitutivo estabelece que "o disposto nesta lei não se aplica à manifestação pacífica de pensamento decorrente da fé e da moral fundada na liberdade de consciência, de crença e de religião de que trata o inciso VI do artigo $5^{\circ}$ da Constituição 
Federal” (BRASIL, 2006a). O fundamento é que o inciso VI do artigo $5^{\circ}$ da Constituição garante a liberdade de consciência, de crença e de religião. O PLC seria votado na Comissão de Direitos Humanos do Senado em 8 de dezembro de 211, mas sua votação foi adiada. No entanto, surge a questão: os indivíduos passam a ter o direito de ofender homossexuais desde que o façam de forma pacífica? Uma ofensa decorrente de crença religiosa estará isenta de punição?

Outrossim, se o substitutivo ao PLC n 122 for aprovado, percebemos como o paradigma da autorrealização, delineado por Honneth, revela-se impreciso. Isso não significa afirmar que a teoria de Honneth inviabilizaria necessariamente a criminalização de manifestação pacífica de pensamento decorrente da fé e da moral fundada na liberdade de consciência, de crença e de religião, tendo em vista a vulnerabilidade moral de membros das comunidades religiosas. No entanto, sua pretensão de atribuir valor positivo às identidades pode inspirar uma certa imprecisão quanto à aplicação do ideal da autorrealização. De fato, pode surgir a seguinte questão: como promover a autorrealização de membros de certa comunidade religiosa - intolerante em relação à orientação sexual - que pretendem exercer a sua liberdade de religião sem ensejar a vulnerabilidade moral e o sofrimento de grupos homossexuais? É precisamente nesse sentido que surgiu uma série de ensaios críticos em relação à imprecisão conceitual ínsita ao ideal de autorrealização. E, recentemente, em resposta às críticas, Honneth tem argumentado que nem todas as experiências de sofrimento e vulnerabilidade moral são eticamente legítimas; no entanto, sua pretensão relativa à atribuição de valor positivo às identidades continua inspirando uma imprecisão conceitual.

Nesse ponto, Veit Bader, sublinha que a ênfase no não reconhecimento é mais adequada que a pretensão de uma teoria positiva do reconhecimento e menos suscetível ao desacordo moral razoável do que esta (Bader, 2007, p. 249-250). Realmente, nós podemos concordar com o princípio da não discriminação de homossexuais, mas divergimos das medidas que atribuem valor positivo e lealdade a esses grupos, tendo em vista o desacordo moral razoável. Ademais, o conteúdo normativo da ideia de bem é mais indeterminado e heterogêneo do que supõe a concepção formal de eticidade. Entre os diversos ensaios críticos, assume relevância a compreensão de Nikolas Kompridis, ao salientar que Honneth não seria preciso em especificar o que significam as condições formais de autorrealização, minimizando o fato de que, muitas vezes, há uma pluralidade de bens que se articulam em caminhos opostos. Nas palavras do autor, "embora permaneça a nível de um pressuposto implícito, Honneth compreende a autorrealização como um bem que apresenta uma estrutura relativamente homogênea e estável. " E conclui: "Mas o significado de qualquer concepção particular de bem, no tempo histórico e espaço cultural, pode ser, e frequentemente é, veementemente impugnado no seu próprio tempo histórico e contexto cultural. "(Kompridis, 2004, p. 334). 
Nesse cenário, para Kompridis, a simples experiência de vergonha, humilhação e sofrimento não significa, por si só, absolutamente nada, podendo ser decorrente de demandas por reconhecimento legítimas ou ilegítimas. Nesse sentido, é clara a assertiva de Kompridis:

... O enfraquecimento conceitual e normativo de uma tradição de questionamento não é um preço que deveria ser também pago facilmente a qualquer hora. Honneth tenta justificar o preço de sua mudança de paradigma normativo com a promessa de um amplo campo de questionamento.

Contudo, a tentativa de Honneth de contrapor-se à minúcia da racionalidade teórica da crítica social parece destinada a compartilhar o fato do qual procura escapar. Mesmo se concedermos ao objetivo de Honneth, a estreiteza da preocupação hegeliana de esquerda com as patologias da razão, igualmente minuciosa, se não mais minuciosa, tal concessão dificilmente pode ser descrita como um ganho teórico. Mas isso não é tudo. Ao abandonar a normatividade da razão pela normatividade da autorrealização, Honneth quebra o elo normativo e conceitual entre razão e crítica, sem o qual esse paradigma não pode funcionar com sucesso como uma Teoria Crítica. [...] (ibidem, p. 331).

Com efeito, na década de noventa, Andreas Kalyvas, professor da New School for Social Research, também não poupou críticas em relação ao ideal da autorrealização, questionando: "como estabelecer a distinção entre sentimentos morais e as expectativas normativas de um grupo reacionário cuja identidade é ameaçada pela democratização e liberalização das sociedades modernas pelos movimentos progressistas?" (Kalyvas, 1999, p. 103). Não obstante, no artigo "Recognition as Ideology", Honneth procurou responder a algumas críticas, analisando uma objeção fundamental que acusaria a sua teoria do reconhecimento de ignorar o fenômeno da sujeição e da dominação por meio de mecanismos ideológicos (Honneth, 2007c). Trata-se da alegação segundo a qual o reconhecimento intersubjetivo seria um mecanismo fundamental capaz de incrementar padrões interpretativos que conduzem a estruturas de dominação. O reconhecimento perde seu caráter de emancipar as relações sociais e transforma-se em um instrumento ideológico de manutenção do status quo. Honneth pretende responder a tal objeção diferenciando formas justificáveis de formas ideológicas de reconhecimento. As práticas institucionais de reconhecimento possuem um conteúdo ideológico na medida em que induzem os sujeitos a criarem uma autoimagem em conformidade com um sistema estabelecido de expectativas de comportamento, funcionando como meio de dominação.

Nessa linha de raciocínio, Honneth exemplifica o recurso à imagem da boa mãe e da exímia dona de casa construída por igrejas, parlamentos e meios de comunicação como instrumentos ideológicos que levam as mulheres a criarem uma autoimagem 
que conduz à acomodação em relação à divisão de trabalho quanto ao gênero. Nas palavras do autor, "somente nas circunstâncias em que as mesmas partes interessadas se revoltam contra práticas dominantes de reconhecimento, nós temos razões para considerarmos uma mera ideologia em relação a esse período histórico" (Honneth, 2007c, p. 327).

Diferentemente, os atos de reconhecimento pressupõem "a demonstração pública de um valor ou uma realização que é atribuída a uma pessoa ou grupo social.” (ibidem, p. 327). Reconhece, entretanto, que, muitas vezes, a demonstração pública de valor social pode incorporar características de dominação e uma certa dificuldade em estabelecer um critério entre formas ideológicas e formas eticamente justificadas de reconhecimento. Sublinha que "à medida que as relações de reconhecimento são transformadas, expandidas e aprimoradas historicamente por meio de novas ênfases nos princípios gerais, há uma maior dificuldade em se identificar formas meramente ideológicas de reconhecimento" (ibidem, p. 341). Conclui que tal identificação se torna possível quando as partes interessadas resistem a certos padrões valorativos, o que permite a ampliação das relações de reconhecimento. Portanto, nem todos os danos psicológicos e nem todas as experiências de sofrimento ensejam demandas justificáveis pela perspectiva da teoria do reconhecimento proposta por Honneth. A grande questão é identificar um critério que permita distinguir entre as formas eticamente justificáveis de reconhecimento e as formas meramente ideológicas.

Em síntese, para Honneth, há uma insuficiência de conteúdo da igualdade, que não atende aos desafios propostos pelo discurso do reconhecimento. Nesse sentido, a possibilidade do surgimento de indivíduos autônomos, que desenvolvem livremente a sua identidade, depende do desenvolvimento intacto de relações de reconhecimento. Para Fraser, a questão é: o que fazer com nossa identidade autônoma? Criar uma sociedade justa na qual todos tenham a possibilidade de participar. A divergência fundamental entre os autores consiste no seguinte pressuposto: para que se forma a identidade? Para Honneth, a possibilidade de desenvolvimento da identidade autônoma seria um fim em si mesma, assumindo a participação na esfera pública uma dimensão instrumental; para Fraser, é um meio para alcançar o fim superior da participação.

Honneth não nega a relevância do debate público para a expansão das relações de reconhecimento e para a tematização de experiências de sofrimento, mas estabelece como objetivo central a formação intacta da identidade individual, sendo a deliberação um instrumento que propicia a distinção entre formas ideológicas de reconhecimento e formas eticamente justificáveis. De um lado, em Fraser, há uma ênfase maior na participação: as concepções de vida boa são submetidas ao escrutínio crítico do debate público, propiciando - por meio de uma participação paritária - constante revisão e discussão sobre certas formas de autorrealização opressoras que conduzem a um quadro de subordinação incompatível com um padrão universal de justiça. 
De outro lado, como a norma da participação paritária é deontológica, tornase possível identificar um contexto de opressão independentemente da felicidade ilusória do sujeito. Essa falta de consciência de uma situação de opressão, típica do escravo feliz, pode se superada por meio da concepção de participação paritária, delineada por Fraser. Daí a relevância das lutas estabelecidas argumentativamente na esfera pública por meio das quais as minorias sexuais tematizam questões relativas a contextos de subordinação, inspirando uma reconstrução dos padrões de interação social. Tais considerações sobre a participação paritária foram explicitadas no seguinte trecho:

... O cerne normativo da minha concepção é a noção de paridade de participação. De acordo com essa norma, a justiça requer arranjos sociais que permitam a todos os membros da sociedade interagir uns com os outros como companheiros. Para a participação paritária ser possível, eu alego que, ao menos, duas condições devem ser satisfeitas. Primeiro, a distribuição de recursos materiais deve ser de tal forma que assegure aos participantes independência e voz. A segunda condição requer que padrões institucionalizados de valores culturais expressem igual respeito para com todos os participantes e assegurem igual oportunidade para alcançar estima social (Fraser, 2001a, p. 29).

Disso se infere, a nosso ver, que o modelo de status de Fraser desvincula-se da perspectiva delineada por Honneth, porquanto as políticas identitárias, ao negligenciarem as estruturas sociais institucionalizadas que oprimem determinados indivíduos, impedem a participação paritária - pois somente por meio do debate público que os indivíduos podem superar contextos de "invisibilidade social" - e o estabelecimento de formas de interação social mais inclusivas.

\section{CONSIDERAÇÕES FINAIS}

Entendemos que os posicionamentos dos ministros Celso de Mello, Gilmar Mendes e Marco Aurélio de Mello revelam a potencialidade do Judiciário para contemplar direitos de uniões homoafetivas, desconstruindo mecanismos institucionais heterossexistas que impedem o surgimento de padrões aprimorados e justos de interação social. Indubitavelmente, o referencial teórico de Nancy Fraser revela-se coerente com os desafios propostos por uma estratégia de fundamentação filosófica da atuação do STF na proteção de minorias sexuais, pois se desconecta de experiências emotivas de sofrimento individual. Propugnamos que o posicionamento específico dos ministros já revela a potencialidade do STF para combater quadros de "invisibilidade social”, inspirando capacidades aprimoradas de autorreferência moral. 
Diante dessa estrutura conceitual, lecionamos que o conceito de invisibilidade social possui recursos teóricos importantes para combater contextos de subordinação, desde que desprovido de experiências de sofrimento, pois o reconhecimento deve ser concebido em uma perspectiva institucional. Honneth configura o reconhecimento sob a dimensão da autorrealização, focalizando a possibilidade de internalização de imagens autodepreciativas. Nesse contexto, a filosofia de Honneth não possui um instrumental teórico capaz de legitimar de maneira precisa formas de tutela jurisdicional voltadas para a proteção de grupos minoritários. A teoria de Fraser, por sua vez, possui recursos teóricos relevantes para compreender formas de judicialização voltadas para a proteção de minorias. Para Fraser, a questão do reconhecimento não se estabelece a partir da perspectiva do escravo feliz, mas de um ponto de vista mais abstrato e objetivo: o ponto de vista moral da justiça. Em face dessa leitura, a autora realiza uma guinada da eticidade hegeliana para a moralidade kantiana. Tais fundamentos filosóficos são relevantes, permitindo ao STF tutelar os direitos fundamentais de casais homoafetivos os quais, ao se desvincularem da perspectiva de escravo feliz, incorporam o ponto de vista de sujeitos engajados em uma participação paritária.

: ARTigo APRovado (01/06/2012) : RECEBIDO EM 29/11/2010

\section{REFERÊNCIAS BIBLIOGRÁFICAS}

BADER, Veit. Recognition, power, and democracy. In: BRINK, Bert van den; OWEN, David. Recognition and power: Axel Honneth and the tradition of critical social theory. Cambridge: Cambridge University Press, 2007. p. 238-269.

BARROSO, Luis Roberto. Diferentes, mas iguais: o reconhecimento jurídico das relações homoafetivas no Brasil. Diálogo Jurídico, Salvador, n. 16, p. 1-32, maio/ago. 2007. Disponível em:

<http://www.direitopublico.com.br>. Acesso em: 3 out. 2010.

BRASIL. Senado Federal. Substitutivo ao Projeto de Lei Complementar no 122/06. Brasília-DF, 2006a. Disponível em:<http://www.senado.gov.br> Acesso em: 1 jan. 2012.

. Supremo Tribunal Federal. Ação Direta de Inconstitucionalidade. União homoafetiva. Ação Direta de Inconstitucionalidade n ${ }^{\circ}$ 4.277-RJ da Procuradoria-Geral da República do Rio de Janeiro. Plenário. Voto do min. relator, Carlos Ayres de Britto. Brasília, DF, j. 4 maio 2011a. Disponível em:

<http://www.stf.jus.br/arquivo/cms/noticiaNoticiaStf/anexo/ADI4277revisado.pdf > . Acesso em: 10 maio 2011.

. Supremo Tribunal Federal. Ação Direta de Inconstitucionalidade. União homoafetiva. Ação Direta de Inconstitucionalidade no 4.277-RJ da Procuradoria-Geral da República do Rio de Janeiro. Plenário. Voto do min. Luiz Fux. Relator: min. Carlos Ayres de Britto. Brasília, DF, j. 5 maio 2011b. Disponível em: <http: / / www.stf.jus.br/arquivo/cms/noticiaNoticiaStf/anexo/ADI4277LF.pdf>. Acesso em: 10 maio 2011. 
. Supremo Tribunal Federal. Arguição de Descumprimento de Preceito Fundamental. União homoafetiva. Arguição de Descumprimento de Preceito Fundamental n ${ }^{\circ} 132$, ajuizada pelo governador do Estado do Rio de Janeiro. Disponível em: <http://www.stf.jus.br/portal/peticaoInicial/ verPeticaoInicial.asp?base=ADPF\&s1=132\&processo=132>. Acesso em: 28 ago. 2009.

. Supremo Tribunal Federal. Arguição de Descumprimento de Preceito Fundamental. União homoafetiva. Arguição de Descumprimento de Preceito Fundamental $n^{\circ} 178$, convertida em Ação Direta de Inconstitucionalidade no 4.277-RJ da Procuradoria Geral da República do Rio de Janeiro. Voto do min. relator, Carlos Ayres de Britto. Brasília, DF, j. 4 maio 2011c. Disponível em: <http://www.stf.jus.br/arquivo/ $\mathrm{cms}$ /noticiaNoticiaStf/anexo/ADI4277revisado.pdf>. Acesso em: 10 maio 2011.

. Supremo Tribunal Federal. Medida Cautelar na Ação Direta de Inconstitucionalidade. União Civil entre Pessoas do Mesmo Sexo. Medida Cautelar na Ação Direta de Inconstitucionalidade n ${ }^{\circ}$ 3.300-DF ajuizada pela Associação de Incentivo à Educação e Saúde de São Paulo e pela Associação da Parada do Orgulho de Gays, Lésbicas, Bissexuais e Transgêneros de São Paulo. Decisão monocrática do ministro Celso de Mello. Brasília, DF, j. 3 fev. 2006b. Disponível em: <http://www.direitohomoafetivo.com.br/anexos/ acao/2006.02.03_-_stf_-_adi_3300_-_decis\%E3o.pdf>. Acesso em: 20 out. 2010.

Supremo Tribunal Federal. Petição. União homoafetiva. Petição no 1984/RS ajuizada pelo Instituto Nacional do Seguro Social. Voto do min. relator, Marco Aurélio de Mello. Brasília, DF, julgado em 10 fev. 2003. Disponível em: <http://www.stf.jus.br/portal/processo/

verProcessoAndamento. asp numero $=1984 \&$ classe $=$ Pet\&codigoClasse $=0 \&$ origem $=J U R \&$ recurso $=0 \&$ tip oJulgamento=M>. Acesso em: 20 out. 2010.

. Supremo Tribunal Federal. Recurso Extraordinário. Art. 226, § $3^{\circ}$, da Constituição Federal.

Recurso Extraordinário $n^{\circ} 406.837$ /SP, ajuizado por Maria Sposito. Voto do min. relator, Eros Grau. Brasília, DF, j. 23 fev. 2005. Disponível em: <http://www.stf.jus.br/portal/jurisprudencia/

listarJurisprudencia.asp?s1 $=\% 28 \% 28406837 \% 29 \% 29+$ NAO+S.PRES. \&base=baseMonocraticas $>$. Acesso em: 20 out. 2010.

. Tribunal de Justiça do Rio Grande do Sul. $4^{\circ}$ Grupo de Câmaras Cíveis. .Embargos

Infringentes. União Homoafetiva. Embargos Infringentes $n{ }^{\circ} 70003967676$ opostos por I.L.M. Voto do min. relator, Sérgio Fernando de Vasconcello Chaves. Porto Alegre-RS, j. 9 mai. 2003. Disponível em: <www.tj.rs.gov.br> Acesso em: 4 out. 2006.

. Tribunal de Justiça do Rio Grande do Sul. $7^{\text {a }}$ Câmara Cível. Apelação Cível. União homossexual. Apelação Cível ñ 7.0001.388.982 ajuizada por espólio de H.O. Voto do min. relator, des. José Carlos Teixeira Giorgis. Porto Alegre-RS, j. 14 mar. 2001. Disponível em: <www.tj.rs.gov.br>. Acesso em: 4 out. 2006.

. Tribunal Superior Eleitoral. Embargos de declaração no Recurso Especial Eleitoral. Art. 14, $\S 7^{\circ}$, da Constituição Federal. Embargos de declaração no Recurso Especial Eleitoral n. ${ }^{\circ} 24.564-P A$ da Procuradoria Regional Eleitoral do Pará. Voto do min. relator, Gilmar Mendes. Brasília-DF, j. 2 out. 2004. Disponível em: <http://www.justicaeleitoral.jus.br/arquivos/tse-recurso-especial-24564>. Acesso em: 20 out. 2010.

BUNCHAFT, Maria Eugenia. A filosofia política do reconhecimento. In: SARMENTO, Daniel. (Org.). Filosofia e teoria constitucional contemporânea. Rio de Janeiro: Lumen Juris, 2009. p. 373-395.

DIAS, Maria Berenice. União homossexual: o preconceito e a justiça. Porto Alegre: Livraria do Advogado, 2006.

FRASER, Nancy. Unruly practices: power, discourse and gender in contemporary social theory. Minneapolis: University of Minnesota Press, 1989.

. Recognition without Ethics? Theory, Culture \& Society, London, v. 18, n. 2-3, p. 21-42, 2001 a.

. Da redistribuição ao reconhecimento?: dilemas da justiça na era pós-socialista. In: SOUZA, Jessé (Org). Democracia hoje: novos desafios para a teoria democrática contemporânea. Brasília: UnB, 2001b. p. 245-282.

. Distorted beyond all recognition: a rejoinder to Axel Honneth. In: FRASER, Nancy;

HONNETH, Axel. Redistribution or recognition?: a political philosophical exchange. London: Verso, 2003b. p. 198-236.

. Justice social in the age of identity politics. In: FRASER, Nancy; HONNETH, Axel. Redistribution or recognition?: A political philosophical exchange. London: Verso, 2003a. p. 7-109. KALYVAS, Andreas. Critical theory at the crossroads: comments on Axel Honneth's theory of recognition. European Journal of Social Theory, London, v. 2, n. 1. p. 99-108, 1999.

HONNETH, Axel. Invisibility: on the epistemology of recognition. Aristotelian Society Supplementary, n. 75, p. 111-126, 2001a. 
Recognition or redistribution?: changing perspectives on the moral order of society. Theory, Culture \& Society, London, v. 18, n. 2-3, p. 43-55, 2001 b.

- Democracia como cooperação reflexiva: John Dewey e a teoria democrática hoje. In: SOUZA, Jessé (Org.). Democracia hoje: novos desafios para a teoria democrática contemporânea. Brasília: UnB, 2001c, p. 63-91.

Luta por reconhecimento: a gramática moral dos conflitos sociais. São Paulo: Ed. 34, 2003a.

Redistribution as recognition: a response to Nancy Fraser. In: FRASER, Nancy; HONNETH, Axel. Redistribution or recognition. Londres; New York: Verso, 2003b, p. 110-197. Between justice and affection: the family as a field of moral disputes. In: the normative foundations of critical theory. Cambridge: Polity Press, 2007a. . Between Aristotle and Kant: recognition and moral obligation. In: the normative foundations of critical theory. Cambridge: Polity Press, 2007b. . Sofrimento de indeterminação: uma reatualização da filosofia do direito de Hegel. São Paulo: Esfera Pública, 2007c.

. The social dynamics of disrespect: on the location of critical theory today. In:

Disrespect: the normative foundations of critical theory. Cambridge: Polity Press, 2007d. . Recognition as ideology. In: BRINK, Bert van den; OWEN, David. Recognition and power: Axel Honneth and the tradition of critical social theory. Cambridge: Cambridge University Press, 2007e.

Centro de Filosofia e Ciências Humanas - UFSC Campus Universitário Trindade Caixa Postal 476 - 88040-970 Florianópolis - SC - Brasil mbunchaftaig.com.br
Maria Eugenia Bunchaft

Doutora e Mestre em Teoria do Estado e Direito CONSTITUCIONAL PELA PUC-RIO

Pós-DOUTORANDA EM FILOSOFIA PELA UFSC

Professora e Pesquisadora do UNIFOA - Centro

UnIVERSITÁRIO DE VOLTA REDONDA 